\title{
Current state of open educational resources in the Arab region: an investigation in 22 countries
}

\author{
Ahmed Tlili ${ }^{*}$, Mohamed Jemni ${ }^{2}$, Mohamed Koutheair Khribi ${ }^{3}$, Ronghuai Huang ${ }^{1}$, Ting-Wen Chang ${ }^{1}$ and Dejian Liu ${ }^{1}$
}

\author{
* Correspondence: ahmed.tlili23@ \\ yahoo.com \\ ${ }^{1}$ Smart Learning Institute of Beijing \\ Normal University, Beijing, China \\ Full list of author information is \\ available at the end of the article
}

\begin{abstract}
While several studies were conducted to investigate the current state of Open Educational Resources (OER) in several regions (e.g., Europe, America, Middle East and MENA), to the best of our knowledge, no study was conducted to cover the entire Arab region, specifically the twenty-two Arab countries. Therefore, to identify the OER gap in this region and then provide recommendations to facilitate OER adoption, this study investigates the current state of OER in the Arab region, specifically in twenty-two Arab countries. The obtained results showed that the OER progress is unbalanced within the Arab countries. Interestingly, several Arab countries are still lack behind when it comes to the application of OER in universities and schools. Finally, several recommendations are identified to several stakeholders, including policy makers and educators, to achieve social justice and facilitate the adoption and use of OER in the Arab region.
\end{abstract}

Keywords: Open educational resources (OER), Open educational practices (OEP), Open education, Arab region, Arabic countries, Policy, Recommendation

\section{Introduction}

Magin (2010) stated that the education level in the Arab region is very low and varies from a country to another. Specifically, the United Nations Educational, Scientific and Cultural Organization (UNESCO) stated that 70 million Arab people are still illiterate due to several reasons, including civil wars, crises or starvation. This has led millions of children to drop out of school, where the majority is girls (Jemni \& Khribi, 2017). To facilitate accessibility to education worldwide and specifically in the Arab region, Open Educational Resources (OER) have started being adopted by various universities and schools. The term Open Educational Resources was first coined at UNESCO's 2002 Forum on Open Courseware and it was defined in the recent UNESCO recommendation on OER as "learning, teaching and research materials in any format and medium that reside in the public domain or are under copyright that have been released under an open license that permit no-cost access, re-use, re-purpose, adaptation and redistribution by others" (UNESCO, 2019).

(c) The Author(s). 2020 Open Access This article is licensed under a Creative Commons Attribution 4.0 International License, which permits use, sharing, adaptation, distribution and reproduction in any medium or format, as long as you give appropriate credit to the original author(s) and the source, provide a link to the Creative Commons licence, and indicate if changes were made. The images or other third party material in this article are included in the article's Creative Commons licence, unless indicated otherwise in a credit line to the material. If material is not included in the article's Creative Commons licence and your intended use is not permitted by statutory regulation or exceeds the permitted use, you will need to obtain permission directly from the copyright holder. To view a copy of this licence, visit http://creativecommons.org/licenses/by/4.0/. 
The OER movement is based on the idea that educational resources (e.g., content, course designs, etc.) should be released under licenses that allow anyone to freely access, retain (download, duplicate, store), reuse, revise (translate, adapt, modify), combine, and-or re-share them (Tlili, Huang, Chang, Nascimbeni, \& Burgos, 2019). OER were adopted at the 2012 World OER Congress (Paris declaration). Since then, there has been increasing interest worldwide in open education initiatives. Particularly, several research studies worldwide have been conducted and reported the importance of OER in reducing learning cost, increasing learning accessibility and improving learning outcomes (Hilton III, Robinson, Wiley, \& Ackerman, 2014; Weller, De Los Arcos, Farrow, Pitt, \& McAndrew, 2015). Additionally, several studies reflected the advantages of OER in achieving the fourth Sustainable Development Goal (SDG4) related to Inclusive and Equitable Quality Education. This is further emphasized by the Qingdao Declaration from the International Conference on Information and Communication Technology (ICT) and Post-2015 Education (UNESCO, 2015):

“Open Educational Resources (OER) provide education stakeholders with opportunities to improve the quality of, and expand access to, textbooks and other forms of learning content, to catalyze the innovative use of content, and to foster knowledge creation. We commit to developing sector-wide strategies and capacity building programmes to fully realize the potential of OER to expand access to lifelong learning opportunities and achieve quality education."

And by The Ljubljana Action Plan from the Second World OER Congress (UNESCO, ):

"If used effectively and supported by sound pedagogical practices, OER allow for the possibility to dramatically increase access to education through ICT, opening up opportunities to create and share a wider array of educational resources to accommodate a greater diversity of educator and learner needs. Increased online access to OER further promotes individualized study, which, when coupled with social networking and collaborative learning, fosters opportunities for pedagogical innovation and knowledge creation."

Furthermore, to support the OER adoption worldwide, UNESCO (2019) highlighted, during its general conference by all member states, five objectives to focus on, namely: (1) Building capacity of stakeholders to create access, use, adapt and redistribute OER;

(2) Developing supportive policy; (3) Encouraging inclusive and equitable quality OER; (4) Nurturing the creation of sustainability models for OER; and, (5) Facilitating international cooperation. While several research studies were conducted to understand the current situation of OER in a given country or region (see for instance, Cronin \& MacLaren, 2018; Hollingshead, Ashburn-Nardo, Stewart, \& Hirsh, 2016; Tlili et al., 2019), no research study, to the best of our knowledge, was found that summarizes the OER progress in the entire Arab region, specifically in the twenty-two Arab countries. It is worth mentioning that some investigations about the OER current state in some regions, such as MENA and Middle East, were conducted by the Commonwealth of Learning (COL), in partnership with UNESCO and the government of Slovenia, but this investigation did not cover all the twenty-two Arab countries (Commonwealth of 
Learning, 2017). Consequently, the current state of OER in the entire Arab region remains unclear. According to the Arab League Educational, Cultural and Scientific Organization (ALECSO), which represents the Arab world's equivalent of UNESCO organization and covers 22 Arab countries to create and coordinate projects and activities in the fields of education, culture, and science in the Arab region, there is no explicit vision or policy to support OER adoption in the Arab region, except in some countries like Bahrain and Saudi Arabia. Additionally, there is a real lack in terms of OER development and use in Arab countries, especially in Arabic language. Educational resources in the Arab region are mostly provided online, on university platforms or specific repositories, without even being open to everyone. This is further seen in the study conducted by ALECSO and the International Telecommunication Union (ITU) on Smart Learning Readiness (ITU, 2014), and in the OER world map. ${ }^{1}$ Therefore, to promote social justice and facilitate OER adoption in the Arab region, this study reports a conducted investigation between ALECSO and the Smart Learning Institute of Beijing Normal University (SLIBNU), which initiated the OER Belt \& Road (OER B\&R) initiative $^{2}$ in 2016, to investigate the current state of OER in the Arab region, specifically in the 22 Arab countries covered by ALECSO. It then presents, based on the obtained results, several guidelines to enhance OER adoption in the region.

The rest of the paper is structured as follows: Section 2 presents the research methodology. Section 3 presents and discusses the obtained results. Finally, Section 4 presents recommendations to empower OER in the Arab region based on the obtained results, concludes the paper and presents future directions.

\section{Methodology}

Based on several created questionnaires in the literature (for instance, UNESCO questionnaire $^{3}$ and University of Leicester questionnaire ${ }^{4}$ ), a questionnaire was developed. It covers four dimensions, as shown in Table 1, namely: (1) Perception towards OER investigates the perception and opinion of Arab region participants towards OER; (2) OER use investigates the frequency of using OER in the Arab region and in which ways; (3) Empowering $O E R$ investigates the launched initiatives and policies in the Arab region to empower OER; and, (4) OER Accessibility investigates the availability of OER for all Arab learners, including those with disabilities. Furthermore, the participants were requested to write down their open inputs and details about each question, if they have any. Finally, the questionnaire was reviewed by five OER experts from both ALECSO and SLIBNU to validate it.

The questionnaire was then disseminated by ALECSO to each Arab country (among the 22 Arab countries covered by ALECSO) via official communication letters sent to the Ministry of Education and Higher education of each country. Additionally, to further involve more stakeholders, including educators and learners, the questionnaire was sent to each member subscribed in the OER database of ALECSO. This database covers Arab stakeholders interested in OER use and adoption.

\footnotetext{
${ }^{1}$ https://oerworldmap.org/resource/

${ }^{2}$ http://sli.bnu.edu.cn/en/Belt__Road/

${ }^{3}$ http://www.unesco.org/new/fileadmin/MULTIMEDIA/HQ/CI/CI/pdf/themes/HewlettQuestionnaire_ English.pdf

${ }^{4}$ https://www2.le.ac.uk/projects/oer/oer-satisfied-survey
} 
Table 1 Proposed questions within the questionnaire

\begin{tabular}{|c|c|}
\hline Dimension & Questions \\
\hline $\begin{array}{l}\text { Perception towards } \\
\text { OER }\end{array}$ & $\begin{array}{l}\text { 1. Does OER enhance learning outcomes and facilitate knowledge sharing? } \\
\text { 2. Does using OER will negatively affecting attending school? } \\
\text { 3. Is the process of creating and publishing OER difficult? }\end{array}$ \\
\hline OER use & $\begin{array}{l}\text { 4. Do teachers/universities in your country provide or use OER in learning? } \\
\text { 5. What barriers do you face in publishing and using OER in your country? } \\
\text { 6. Are you aware of using open licenses (e.g., Creative Commons)? } \\
\text { 7. What types of OER content you want to use or provide? } \\
\text { 8. In which language you want to use OER? }\end{array}$ \\
\hline Empowering OER & $\begin{array}{l}\text { 9. Are there any OER platforms offered by your country? } \\
\text { 10. Are there any provided Massive Open Online Courses (MOOCs) in your country? } \\
\text { 11. Are there any policies/strategies provided by your ministry of education/higher } \\
\text { education to promote OER in your country? } \\
\text { 12. Are there any initiatives (personal, institutional, regional or national) to promote OER } \\
\text { in your country }\end{array}$ \\
\hline OER Accessibility & 13. Are there OER for students with disability in your country? \\
\hline
\end{tabular}

\section{Results and discussion}

Seven hundred thirty-five participants answered this questionnaire. The country distribution of the participants is presented in Fig. 1, where it is seen that they came from different 21 countries (among 22 countries covered by ALECSO). Particularly, only participants from Comoros (country) did not participate in this survey. This can be explained with Comoros does not currently have any OER progress. Therefore, no participant has answered this survey. Consequently, we could deduce that the provided findings about the current state of OER in the Arab region, in the next subsequent sections, can be generalized as $99 \%$ of the countries participated in this survey.

\section{Perception towards OER}

As a basic step, the first question was about collecting the opinion of participants (teachers, policy makes, government agents, etc.) about the impact of OER on learning practices. This was to understand if there was enough awareness in the Arab region about OER as a paradigm to enhance learning outcomes and facilitate knowledge sharing as highlighted in several studies. The obtained results are shown in Fig. 2 (a). Particularly, it is seen from Fig. 2 (a) that most of the participants are aware of the advantages of OER in learning, where only $1 \%$ have neutral opinion about the positive impact of OER on learning outcomes. Additionally, to investigate if the Arab

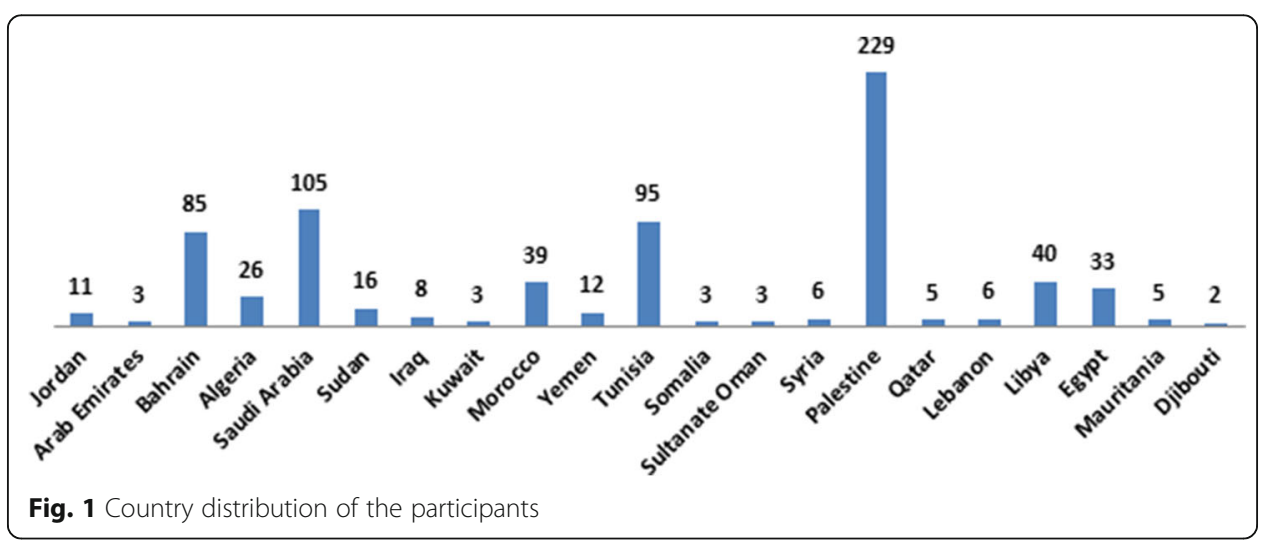




\section{(a)}

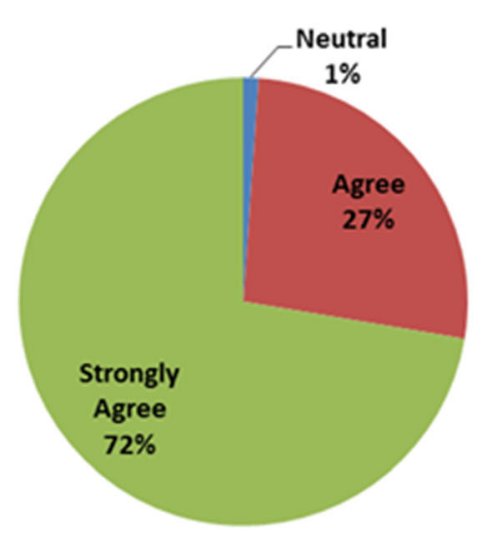

(b)
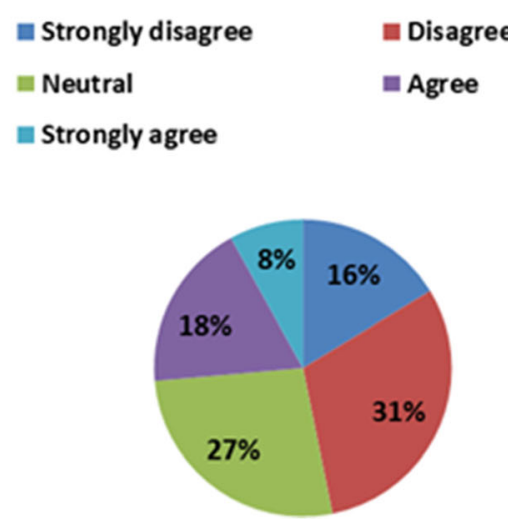

Fig. 2 Perception of participants towards OER in learning

participants share the common OER misinterpretation, namely "OER can negatively affect school attendance", their feedback about this matter was collected and analyzed, as shown in Fig. 2 (b). It is seen that $47 \%$ of the participants do not share this idea, and they disagree or strongly disagree with it, while $27 \%$ of the experts are neutral.

After that, an investigation was conducted about the perception of Arab participants towards creating and publishing OER in the Arab region, as shown in Fig. 3. Interestingly, it is seen that $73 \%$ (agree and strongly agree) of the participants think that the process of creating and publishing OER is a difficult process in the Arab region. To conclude, it is seen that the awareness about OER advantages in learning in the Arab region is high since ALECSO has organized several workshops and conferences in several Arab countries to achieve this purpose. However, it is seen that the participants in the Arab region still think that creating and publishing OER is not an easy step. Hence,

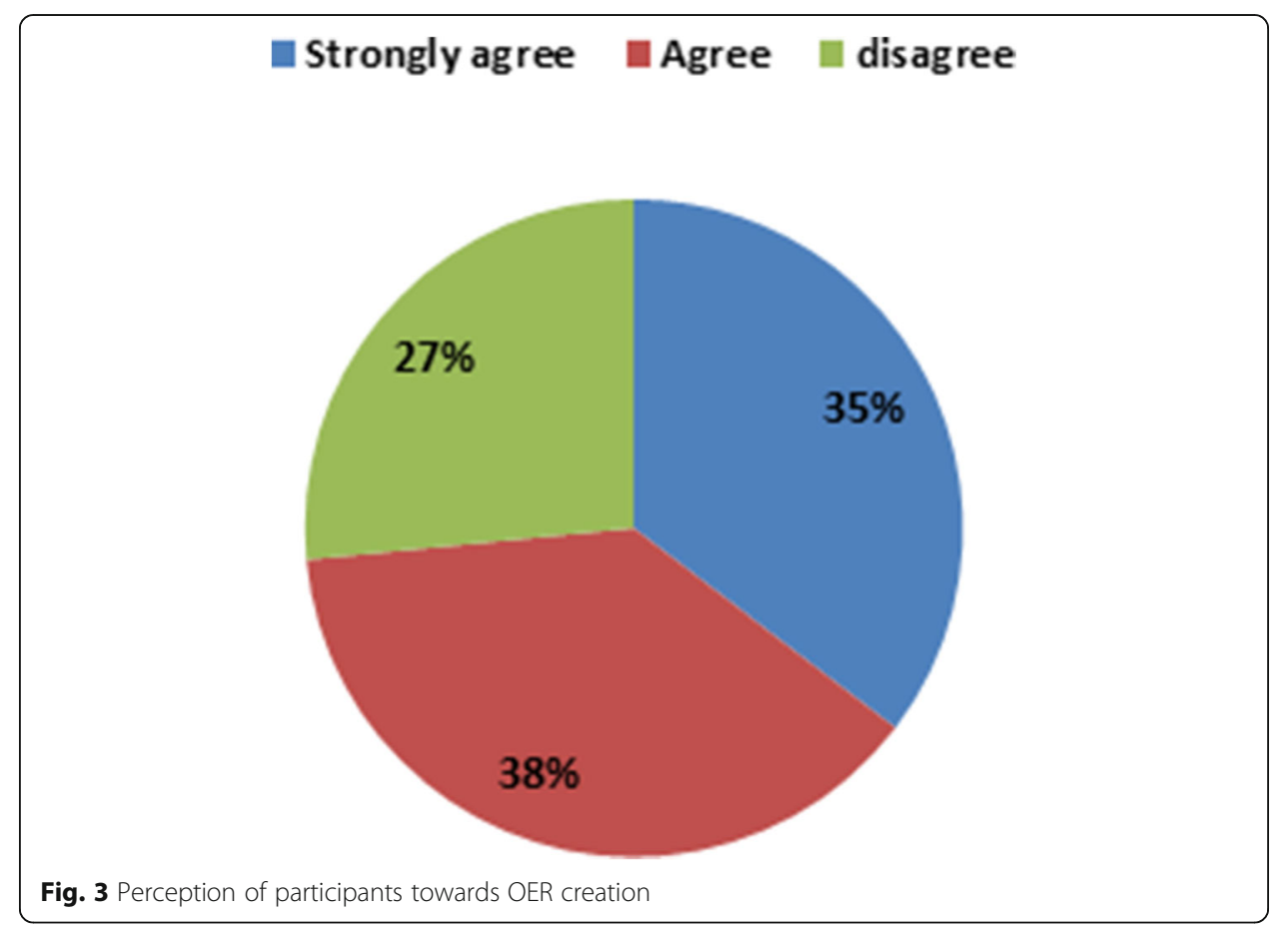


the next subsequent section investigates the OER use in the Arab region to further understand the reasons of having this perception.

\section{OER use}

As shown in Fig. 4, it is seen that 43\% (313 participants) and 37\% (270 participants) of the participants reported that OER is not being used in their country, or being used with limited content respectively. However, it is seen that only $21 \%$ of the participants reported that OER is being used in their countries. According to Al Arabiya News (2013), online Arabic resources in general (not only OER) represent only $3 \%$ of the overall Internet content. This shows the urgent need to publish more online Arabic content in general and open in particular. Specifically, it is found that $38 \%$ of the participants who reported that "OER is being used in their countries" are from Saudi Arabia, while 27\% of them are from Bahrain. To further understand this, the inputs (additional comments given by the participants about OER use in their countries) of participants given from these two countries (Saudi Arabia and Bahrain) were analyzed and discussed below.

It is found that Saudi Arabia has created a popular OER repository called Shms, ${ }^{5}$ sponsored by several universities, which contains 52,788 courses, 378,523 open educational resources, and 24,929 learning activities, as well as a MOOCs provider called Rwaq (https://www.rwaq.org/). Furthermore, many initiatives and programs were set in order to promote the use and development of OER in higher education in Saudi Arabia. In this regard, a specific OER program entitled "The Saudi National OER program" was launched, aiming at enhancing the educational content to support quality education and contribute in providing more educational opportunities in the kingdom. The main achievements so far encompass the creation of the national OER platform Shms that offers secure and reliable educational resources for all, partnerships with international institutions and organizations, localizations of the OER and building high quality Arabic educational content, etc. Bahrain has also created a popular OER repository called "my digital library '(مكتبتي الرقمية)" which contains courses for primary and

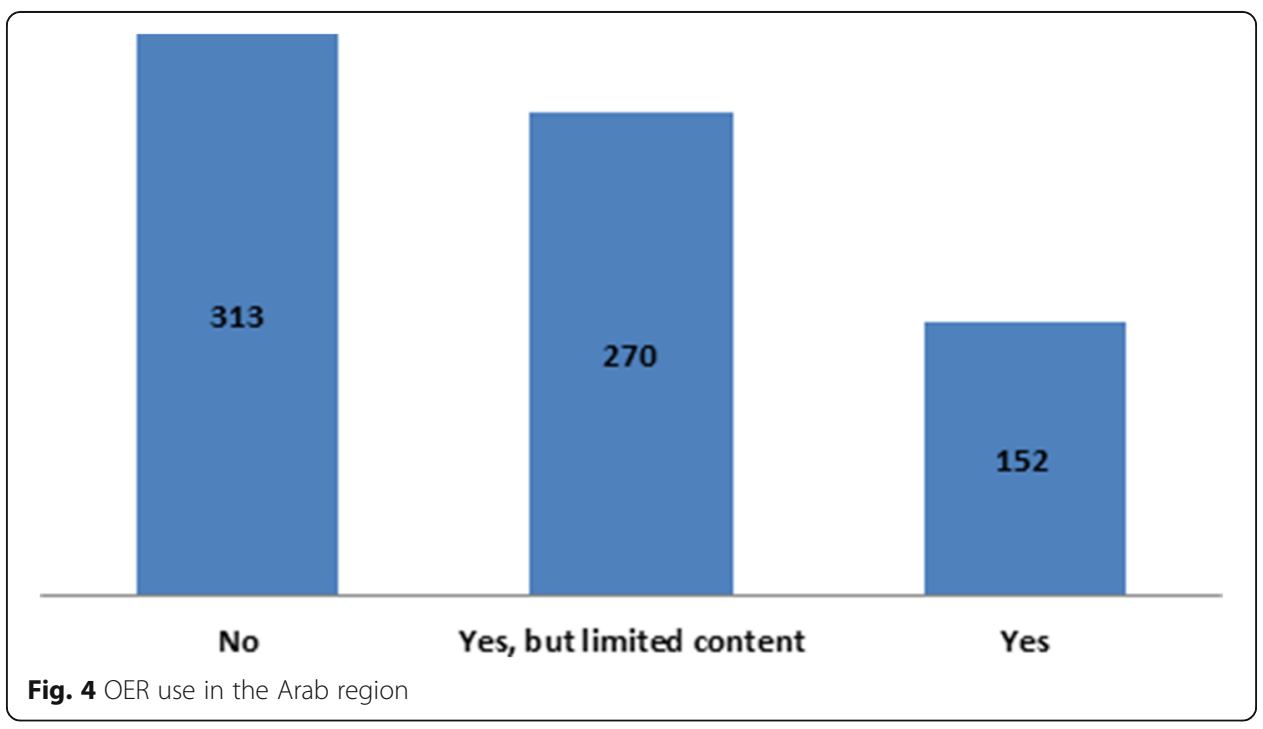


secondary school students, as well as trainings in different fields for students. This repository has won the best ISESCO (Islamic Educational, Scientific and Cultural Organization) OER initiative in 2018. Further details about the OER initiatives in the Arab world are presented in the next subsequent section (See section 3.3).

Particularly, from the Arab participants' inputs (additional comments given by the participants about OER use in their countries), it is seen that OER is used in a very simple way by accessing open resources online without being used in a structured ways for effective open teaching and collaboration. This should be changed as using open educational practices in universities can enhance learning outcomes and teacher professional development. Ehlers (2011) defined OEP as "practices which support the (re) use and production of Open Educational Resources through institutional policies, promote innovative pedagogical models, and respect and empower learners as co-producers on their lifelong learning paths." Similarly, the recently approved UNESCO (2019) OER recommendation mentioned that "the judicious application of OER, in combination with appropriate pedagogical methodologies, well-designed learning objects and the diversity of learning activities, can provide a broader range of innovative pedagogical options to engage both educators and learners to become more active participants in educational processes and creators of content as members of diverse and inclusive Knowledge Societies." For instance, using OER in universities and schools can help students learn digital literacy (review, evaluate, modify) which is one of the twenty-first century skills.

Furthermore, to investigate the factors that made the Arab region participants face difficulties while developing and publishing OER, their answers were collected and analyzed as shown in Fig. 5. Specifically, it is seen that the absence of motivational factors is one of the common problems which made the Arab participants do not develop and publish OER (26\%), followed by lack of time (21\%), copyright (20\%) and the absence of authoring tools (17\%). To overcome these issues in other countries, it is seen, for instance, that China gives bonuses to teachers who contribute to enriching the national OER repositories with their own OER (Tlili et al., 2019). Additionally, to overcome the lack of time issue, the process of creating OER must be timeless and this can be achieved by developing authoring tools which can help in creating OER with simple steps.

Furthermore, an OER can be legally considered as long as it is used with an open license that defines how that OER can be used. Particularly, World Intellectual Property Organization stated that open licenses help to protect two rights of OER authors and publishers (WIPO, 2016), namely: (1) Financial rights help OER publishers and authors gain money from others using their work; and, (2) Moral rights allow authors and creators to take certain actions to preserve and protect their link with their work. Specifically, Creative Commons (CC), launched in 2002, is currently the most used open license with OER. However, it is found that $48 \%$ of the Arab participants do not know about CC, while $24 \%$ know CC but with limited information. This shows that the Arab region participants are having low awareness about open licenses which can protect their published OER. This reflects the reason of raising big concern about copyright (as highlighted in Fig. 5).

\footnotetext{
${ }^{5}$ https://shms.sa/

${ }^{6}$ http://eteacher.edunet.bh/course/view.php?id=615
} 


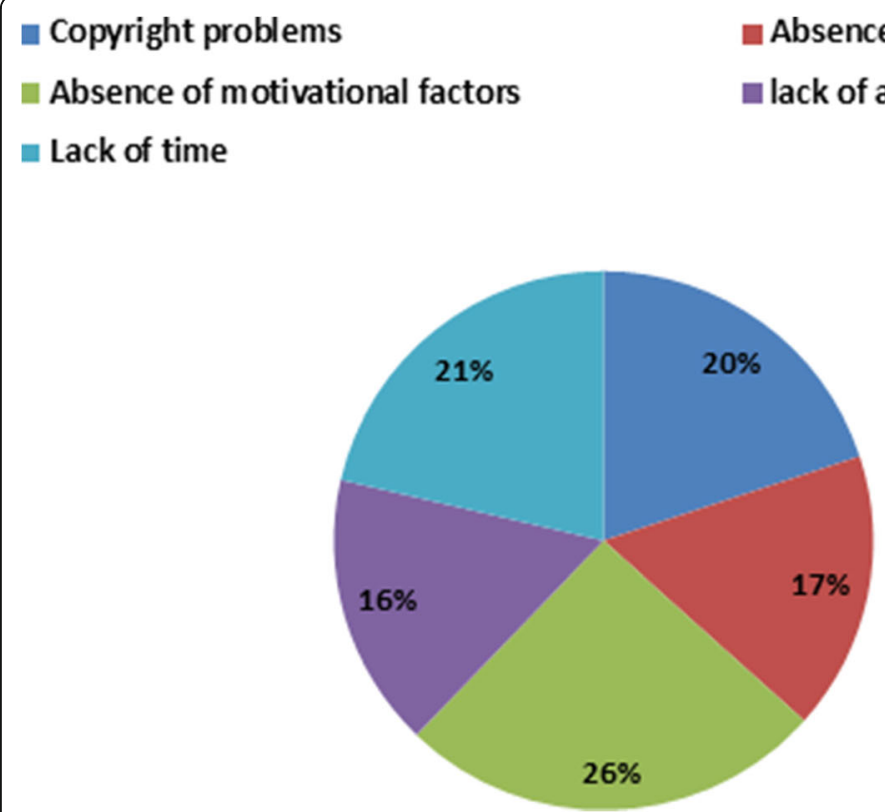

Fig. 5 OER challenges in the Arab region

On the other hand, it is seen that very limited countries initiated some policies to support open licenses. For instance, one of the objectives covered by the Bahrain OER policy is "ensuring that all the learning materials produced by teachers and students, by the Ministry of Education and supporting materials developed for teachers using public funds will adopt the CCBYNC license" (Miao, Mishra, Orr, \& Janssen, 2019, p. 39). It should be noted that online resources in the Arab region are protected by different copyright laws, depending on each country. However, the growing interest in openness made several Arab countries start using open licenses. For instance, existing educational resources published on Shms platform are licensed using $\mathrm{CC}$ licenses enabling thus their free distribution. Therefore, raising awareness of open licensing, as well as implementing them in the Arab region can allow Arab people to use, adapt and share education materials.

Besides, OER are mostly provided in digital formats (to facilitate their reuse and distribution in different educational settings) and could be in different learning types (e.g., video audio, etc.). Therefore, to investigate the OER types that the Arab region participants want to use, their answers were collected and analyzed, as shown in Fig. 6. It is seen that most of them want to have open e-books as this could help reduce the cost of purchasing textbooks in the Arab region. Particularly, it is seen that several Arab families now cannot afford to buy textbooks for their children and this causes drop out from schools and universities. In this context, United States, Pakistan and Bangladesh have started replacing textbooks with open ebooks to reduce learning costs (Feldstein et al., 2012; Miao et al., 2019). Additionally, as a second type of OER, it is seen that the participants prefer having open video lectures and PDF/ PPT courses. This could be explained by video and PDF/PPT types can easily be reused in any educational setting to enrich the learning experience.

Finally, it is seen that the Arab region participants prefer the OER in Arabic (85\%) since there is a lack of published Arabic resources online, followed by English (75\%) and French (25\%) and this is totally understandable since English is the second 


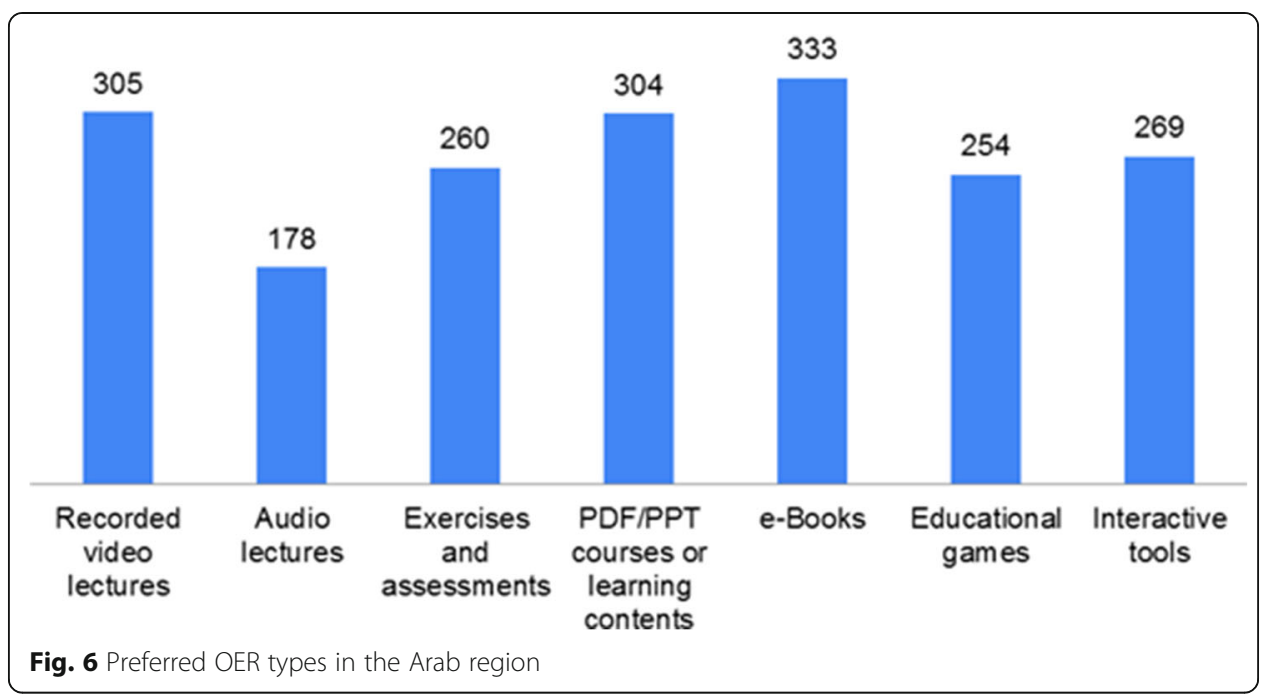

language in most Arabic countries, as well as French. Finally, 5\% of the Arab region participants also reported that they want to use OER in Chinese and Spanish. This could be explained with the fact that currently several institutional collaborations between the Arab region and China and Spain are being established.

Afterwards, it was important to investigate whether the governments in the Arab region support empowering OER through several policies, in order to put the OER advantages into practices. A policy is a set of planned practices, actions and behaviors to achieve a specific goal (OER adoption and use, in this study).

\section{Empowering OER}

When the Arab participants were asked if governments in the Arab region are supporting the OER initiatives, $28 \%$ of them answered with "No" while $49 \%$ of them reported that Arab region governments are supporting OER, but without clear vision. Furthermore, it is seen the absence of strategies or models for sustainable OER projects, i.e., how OER could maintain money and last for years without students paying tuition fee just like in non-open online learning. (Mintzberg, H., Ahlstrand, B., \& Lampel, J. 2009) stated that an effective policy should cover three perspectives, namely: (1) Seeing ahead and seeing behind: This perspective focus on building future vision based on the past, i.e. what it is already achieved; (2) Seeing down and seeing below: This perspective aims to look to the context from above to generalize experiences and from below to deeply understand the context and how experiences occur; and, (3) Seeing beside and seeing beyond: This perspective supports "thinking outside the box" to find innovative solutions for the current challenges of a given situation.

Furthermore, based on the participants' inputs (additional comments given by the participants about empowering OER in their countries), it is seen that only few initiatives have been launched to empower OER. These initiatives, as shown in Table 2, could be classified into four categories, namely creating open universities, developing OER repositories and Massive Open Online Courses (MOOCs) providers, launching OER regulations, and organizing e-learning trainings and OER seminars/workshops. Particularly, it is seen that only few governmental and institutional policies are 
launched in the Arab region, however no organizational OER policies are reported in the Arab region.

To overcome this issue, it is a priority to launch new policies and initiatives that empower OER adoption. These policies and initiatives could be governmental, institutional or even individual. For instance, to empower OER in China, the government launched in 2011 the Construction of National Quality Open Courses $\left(\mathrm{NQOC}^{7}\right)$ initiative. This initiative focuses on sharing quality educational resources, showcasing best practices in teaching, encouraging independent learning, and supporting open learning using online platform. It also involves the building of 1000 quality open video courses (QOVC) and 5000 quality open resource course (QORC). Also, as part of its commitment to open education, the Edinburgh University, Scotland encouraged its employers (educators, administrators, etc.) to create and use OER for better learning outcomes. Furthermore, several tools are found which can help develop strategies or policies (Miao et al., 2019), such as Institutional OER Policy Template of Commonwealth of Learning (COL) which provides ready-to-use template for drafting an Institutional OER policy. The College and University OER Policy Development Tool, created by Lumen Learning, is for college and university governance officials, as well as individuals who have responsibility for developing institutional policy, to promote the utilization of OER and scale efforts to achieve full OER programs. It is also available as a web-based tool. The Feasibility Protocol is an instrument for the executive management of higher education institutions, providing guidance in making informed decisions about institutional adoption of OER (Bossu, Brown, \& Bull, 2013).

\section{OER accessibility}

Based on the inputs (additional comments given by the participants about OER Accessibility in their countries) of the Arab region participants, it is seen that accessing OER is not easy, due to several mentioned issues, including the difficulty of finding a specific OER or the lack of awareness about OER repositories and finally lack of ICT infrastructure in some Arab countries. Similarly, de los Arcos and Weller (2018) found that technical problems limit Global South teachers from using OER. Therefore, it is crucial to provide ICT in each country for better adoption and use of OER. Also, developing lowcost technologies to help accessing OER offline would increase OER accessibility especially in Arab rural areas where Internet infrastructure is not established. For instance, the Aptus device from COL allows users to offline use $128 \mathrm{~GB}$ of digital learning platforms and content without the need for grid electricity. This tool can especially be used in rural areas where Internet is not provided. Also, 101 ppt software provides several ready resources (e.g., animation, courses, assignments) that someone can easily access too without Internet and integrate it into his/her course.

To further support OER accessibility in the Arab region (22 countries), ALECSO created the OER Commons ALECSO Hub, ${ }^{8}$ with bi-lingual (English and Arabic) user interface which contains OER content from the 22 Arab countries. In this Hub, the user can add, search and download OER. Additionally, he/she can create OER using an online authoring tool developed within the hub. Furthermore, to increase accessibility to education, ALECSO in collaboration with the secretary Clinton launched in 2013

${ }^{7}$ http://www.icourses.cn/home/ 
Table 2 OER initiatives in the Arab world

\begin{tabular}{|c|c|c|}
\hline Initiative category & Country & Initiative \\
\hline \multirow[t]{3}{*}{ Creating open Universities } & Sudan & Open University of Sudan \\
\hline & Palestine & Al-Quds Open University \\
\hline & $\begin{array}{l}\text { Saudi } \\
\text { Arabia }\end{array}$ & Arab Open University \\
\hline \multirow{8}{*}{$\begin{array}{l}\text { Developing OER repositories and } \\
\text { MOOCs providers }\end{array}$} & \multirow{2}{*}{$\begin{array}{l}\text { Saudi } \\
\text { Arabia }\end{array}$} & Shms repository (https://shms.sa/) \\
\hline & & Rwaq (https://www.rwaq.org/) \\
\hline & Qatar & $\begin{array}{l}\text { Qatar University institutional repository (https://qspace.qu.edu. } \\
\text { qa/) }\end{array}$ \\
\hline & Bahrain & $\begin{array}{l}\text { "my digital library (ككتبني الرقمية) http://eteacher.edunet.bh/ } \\
\text { course/view.php?id=615) }\end{array}$ \\
\hline & Jordan & Edraak (https://www.edraak.org/en/) \\
\hline & \multirow[t]{2}{*}{ Egypt } & Supercourse of Science \\
\hline & & $\begin{array}{l}\text { Digital Assets Repository (DAR) system at the Library of } \\
\text { Alexandria }\end{array}$ \\
\hline & Tunisia & Virtual University of Tunis \\
\hline \multirow[t]{14}{*}{ Launching OER regulations } & \multirow[t]{2}{*}{ Bahrain } & $\begin{array}{l}\text { The Bahrain OER policy states as one of its objectives is } \\
\text { ensuring that all the learning materials produced by teachers } \\
\text { and students, by the Ministry of Education and supporting } \\
\text { materials developed for teachers using public funds will adopt } \\
\text { the CC-BYNC license. }\end{array}$ \\
\hline & & $\begin{array}{l}\text { The Open Data Platform in Bahrain is a governmental initiative } \\
\text { launched to establish a unified centre, to make public data } \\
\text { available to the public and develop a strategy for open data, in } \\
\text { order to promote transparency and encourage e-participation. }\end{array}$ \\
\hline & \multirow[t]{2}{*}{ Morocco } & Open Digital Space for the Mediterranean (e-Omed) project \\
\hline & & $\begin{array}{l}\text { GENIE programme, which incorporates OER, and the strategy } \\
\text { adopted by the National Laboratory of Digital Resources of the } \\
\text { Ministry of Education, where a reference to OER is presented in } \\
\text { draft ministerial notes regarding validation and certification of } \\
\text { digital resources that are in development }\end{array}$ \\
\hline & Lebanon & $\begin{array}{l}\text { Notre Dame University-Louaize (NDU) University-wide Strategic } \\
\text { Plan Vision 20/202015-2020, which calls for continuous training } \\
\text { of faculty members and students on the use of OER in teaching } \\
\text { and learning }\end{array}$ \\
\hline & Sudan & $\begin{array}{l}\text { Open University of Sudan provides } 430 \text { textbooks as open } \\
\text { content }\end{array}$ \\
\hline & Algeria & $\begin{array}{l}\text { University of Bejaia encourages staff and students to use, create } \\
\text { and publish OERs }\end{array}$ \\
\hline & Kuwait & Towards developing national OER policy \\
\hline & Qatar & Towards developing national OER policy \\
\hline & Jordan & $\begin{array}{l}\text { Ministry of Education, in partnership with UNESCO, launched } \\
\text { the Open Education Management Information System (EMIS) in } \\
2016 .\end{array}$ \\
\hline & Oman & National OER Policy \\
\hline & \multirow{3}{*}{$\begin{array}{l}\text { Saudi } \\
\text { Arabia }\end{array}$} & Developing national OER policy \\
\hline & & Developing the OER ecosystem from the supply \\
\hline & & $\begin{array}{l}\text { The Saudi National OER program includes the following } \\
\text { objectives: (1) offer quality education for Arab citizens in the } \\
\text { region and develop OER leadership in the region; (2) provide } \\
\text { educational opportunities for Arabic speakers; (3) contribute to } \\
\text { the quality of lifelong education; (4) enhance the quality and } \\
\text { accessibility of teaching and learning resources; (5) strengthen } \\
\text { the coordination in design, development and quality assurance } \\
\text { of OER; (6) establish the best open educational practices, } \\
\text { products, and outstanding processes through self-evaluation }\end{array}$ \\
\hline
\end{tabular}


Table 2 OER initiatives in the Arab world (Continued)

\begin{tabular}{|c|c|c|}
\hline Initiative category & Country & Initiative \\
\hline & & and peer review. \\
\hline \multirow{9}{*}{$\begin{array}{l}\text { Organizing e-learning trainings } \\
\text { and OER seminars/workshops. }\end{array}$} & Morocco & The national OER Strategy Forum \\
\hline & Tunisia & $\begin{array}{l}\text { The 1st International Open Educational Resources (OER) } \\
\text { Seminar }\end{array}$ \\
\hline & Libya & $\begin{array}{l}\text { International Libyan conference on open educational resources } \\
\text { and digital warehouse }\end{array}$ \\
\hline & \multirow{2}{*}{$\begin{array}{l}\text { Saudi } \\
\text { Arabia }\end{array}$} & OER Workshop 2014, Riyadh \\
\hline & & $\begin{array}{l}\text { About } 1000 \text { OER Champions are being trained from PE/HE/LLL } \\
\text { across the country }\end{array}$ \\
\hline & \multirow[t]{2}{*}{ Lebanon } & Open Education Week 2017 \\
\hline & & CC Summit 2015 \\
\hline & Oman & $\begin{array}{l}\text { Open Educational Resources Workshop at Higher College of } \\
\text { Technology, } 2017\end{array}$ \\
\hline & Egypt & OER National Strategy Forum, 2016 \\
\hline
\end{tabular}

the Open Book Project which aims to develop open courseware in science and technology, as well as train educators to use and create OER (Jemni \& Khribi, 2017).

Besides, despite the growing number of OER (Hoosen \& Butcher, 2019) and the policy attention devoted to OER accessibility, as demonstrated by the presence of guidelines to increase the accessibility of OER within the Ljubljana OER action Action Plan (UNESCO, 2017a, b), the extent to which OER are actually accessible is currently being questioned (Zhang et al., 2020). This is further seen in the Arab region where $68 \%$ of the participants reported that there is no OER for learners with disabilities. Particularly, from a literature review conducted by Zhang et al. (2020) about OER and disability, only one study is found from Tunisia which discussed the accessibility of MOOCs for learners with disabilities, conducted by Brahim, Khribi, and Jemni (2017). Therefore, much attention should be put to provide accessible OER for learners with disabilities.

\section{Recommendation, conclusion and future direction}

Based on the obtained results, it is seen that the adoption and use of OER in the Arab region is still in its infancy. Particularly, it is seen that OER progress is unbalanced in the Arab region and some countries still did not even start using OER, such as Comoros. This should be changed to achieve social justice and to enhance learning outcomes. Consequently, based on the obtained findings, several recommendations are presented below.

- Very limited initiatives and policies are launched in the Arab region to empower OER, mostly are governmental ones. This should be changed by involving more stakeholders, including university directors, educators, textbook publishers, ICT and Internet providers, etc. Additionally, for a policy to achieve the given goal or vision, an analysis of the current context should be conducted, with a specification of the involved stakeholders, duration and expected outcomes. Furthermore, international

$\overline{{ }^{8} \text { https://www.oercommons.org/hubs/ALECSO }}$ 
policies can also be readopted to a particular context in the Arab region. Besides, several ready-made tools and policies (as described above) are found which can be reused in a specific context.

- More awareness about open licenses and the way to use them to protect OER publishers is crucial. This could be achieved by organizing several workshops and summits related to open licenses and copyright in the Arab region. Additionally, more awareness should be raised about how OER could increase learning accessibility to learners with disabilities.

- To increase OER accessibility, several governmental or institutional policies to achieve this goal are needed. For instance, bonus money can be given by institutions in the Arab region to encourage teachers to develop and publish OER. Also, institutions can make "publishing in open access journals" as one of the criteria for academic promotions. Additionally, providing trainings about using standardized metadata for the published resources are needed, as well as how to search, assess and select a given OER. Furthermore, Low-cost technologies which facilitate offline accessibility to OER should be developed. This allows OER accessibility even in regions where Internet is not provided (e.g., rural areas).

- More tools are needed to encourage and facilitate developing OER in the Arab region. This could be achieved by providing more authoring tools that facilitate OER creation. Particularly, developing more inclusive authoring tools (that work with different functional diversities) is needed to provide more accessible content to learners with disabilities.

- Researchers and practitioners should consider different accessibility guidelines (e.g., WCAG 2.0) while developing their OER platforms, tools and devices. This helps in providing an effective approach to accessibility, functional diversity and e-inclusion in educational settings.

- OER is being used in a very primitive way, i.e., by simply accessing published OER online. This should be changed and replaced with more structured and innovative Open Educational Practices (OEP), such as open curriculum, pedagogy and assessment, to enhance learning outcomes and skills within learners.

- Sustainable OER models and strategies should be developed to maintain OER projects and support lifelong learning. Additionally, more partnership between the Arab countries should be established to encourage the knowledge of sharing and increase OER accessibility in the entire Arab region.

The findings of this study, based on the presented recommendations, can facilitate the adoption and implementation of OER in the Arab region by different stakeholders. This can facilitate knowledge sharing within the Arab region and also between different regions. Consequently, inclusive and lifelong learning will be established where no one is left behind. However, it should be noted that this study has several limitations that should be acknowledged. For instance, the obtained results are mainly based on the survey method. Therefore, more research instruments will be used in the future to collect different data (perception data, learning performance data, etc.) from different stakeholders (learners, educators, policy makers, etc.). However, despite this limitation, this study presented a solid ground to fill the research gap about the limited 
information on the current state of OER in the Arab region, specifically in the twentytwo countries.

\section{Acknowledgements}

The authors would like to thank Prof. Mohamed Ould Amar, General Director of the Arab League Educational, Cultural and Scientific Organization (ALECSO), for his support and help to realize this study.

\section{Authors' contributions}

Each author contributed evenly to this paper. The authors read and approved the final manuscript.

\section{Funding}

This study was funded by the Arab League Educational, Cultural and Scientific Organization (ALECSO) and the Smart Learning Institute of Beijing Normal University (SLIBNU).

\section{Availability of data and materials}

The datasets generated and/or analyzed during the current study are not publicly available due to privacy reasons but are available from the corresponding author on reasonable request.

\section{Competing interests}

The author declares that they have no competing interests.

\section{Author details}

${ }^{1}$ Smart Learning Institute of Beijing Normal University, Beijing, China. ${ }^{2}$ Arab League Educational, Cultural and Scientific Organization, Tunis, Tunisia. ${ }^{3}$ National Higher Engineering School of Tunis, University of Tunis, Tunis, Tunisia.

Received: 4 February 2020 Accepted: 18 March 2020

Published online: 06 April 2020

\section{References}

Al Arabiya News. (2013). Google: Arabic content ranks eighth on the internet. http://english.alarabiya.net/en/media/digital/2 013/12/01/Google-Arabic-content-ranks-eighth-on-the-internet.html

Bossu, C., Brown, M., \& Bull, D. (2013). Feasibility protocol: An instrument to assist institutional adoption of OER. University of New England Retrieved from http://dehub.edu.au/publications/occasional-papers.

Brahim, H. B., Khribi, M. K., \& Jemni, M. (2017). Towards accessible open educational resources: Overview and challenges. In 2017 6th International Conference on Information and Communication Technology and Accessibility (ICTA) (pp. 1-6). IEEE.

Commonwealth of Learning. (2017). REPORT MENA Regional Consultation on Open Educational Resources. Accessed from http://rcoer.col.org/uploads/2/2/8/4/22841180/mena_rcoer_report_18april.pdf

Cronin, C., \& MacLaren, I. (2018). Conceptualising OEP: A review of theoretical and empirical literature in open educational practices. Open praxis, 10(2), 127-143.

de los Arcos, B., \& Weller, M. (2018). A tale of two globes: Exploring the north/south divide in engagement with open educational resources. In J. Schöpfel \& U. Herb (Eds.), Open divide: Critical studies on open access (pp. 147-155). Sacremento: Library Juice Press.

Ehlers, U.-D. (2011). Extending the territory: From open educational resources to open educational practices. The journal of open, flexible, and distance learning, 15(2), 1-10.

Feldstein, A., Martin, M., Hudson, A., Warren, K., Hilton III, J., \& Wiley, D. (2012). Open textbooks and increased student access and outcomes. European Journal of Open, Distance and E-Learning, 15(2).

Hilton III, J. L., Robinson, T. J., Wiley, D., \& Ackerman, J. D. (2014). Cost-savings achieved in two semesters through the adoption of open educational resources. The International Review of Research in Open and Distributed Learning, 15(2), 6784

Hollingshead, N. A., Ashburn-Nardo, L., Stewart, J. C., \& Hirsh, A. T. (2016). The pain experience of Hispanic Americans: A critical literature review and conceptual model. The Journal of Pain, 17(5), 513-528.

Hoosen, S., \& Butcher, N. (2019). Understanding the impact of OER: Achievements and challenges. Moscow: UNESCO IITE.

ITU. (2014). Guidelines for Formulating National Strategies on Smart Learning. Accessed from http://www.alecso.org/nnsite/ pdf/201611062004.pdf

Jemni, M., \& Khribi, M. K. (2017). Toward empowering open and online education in the Arab world through OER and MOOCs. In Open education: from OERs to MOOCs (pp. 73-100). Berlin, Heidelberg: Springer.

Magin, S. (2010). Illiteracy in the Arab region: A meta study. Retrieved from http://www.gial.edu/images/gialens/vol4-2/MaginArab-llliteracy.pdf

Miao, F., Mishra, S., Orr, D., \& Janssen, B. (2019). Guidelines on the development of open educational resources policies. UNESCO Publishing.

Mintzberg, H., Ahlstrand, B., \& Lampel, J. (2009). Strategy safari: The complete guide through the wilds of strategic management. London, UK: FT Prentice Hall.

Tlili, A., Huang, R., Chang, T. W., Nascimbeni, F., \& Burgos, D. (2019). Open educational resources and practices in China: A systematic literature review. Sustainability, 11(18), 4867.

UNESCO. (2015). Qingdao declaration (2015): Seize digital opportunities, lead education transformation. Paris: UNESCO Retrieved from http://unesdoc.unesco.org/images/0023/002333/233352m.pdf.

UNESCO. (2017a). Ljubljana OER action plan 2017. Retrieved October 5, 2019, from https://en.unesco.org/sites/default/files/ ljubljana_oer_action_plan_2017.pdf

UNESCO. (2017b). Second World OER Congress: Ljubljana OER action plan. Retrieved from https://en.unesco.org/sites/default/ files/jubljana_oer_action_plan_2017.pdf 
UNESCO. (2019). UNESCO recommendation on open educational resources (OER). Retrieved from https://en.unesco.org/ news/unesco-recommendation-open-educational-resources-oer

Weller, M., De Los Arcos, B., Farrow, R., Pitt, B., \& McAndrew, P. (2015). The impact of OER on teaching and learning practice. Open Praxis, 7(4), 351-361.

WIPO. (2016). Understanding copyright and related rights. World intellectual property organization. Retrieved from http:// www.wipo.int/edocs/pubdocs/en/wipo_pub_909_2016.pdf

Zhang, X., Tlili, A., Nascimbeni, F., Burgos, D., Huang, R., Chang, T. W., et al. (2020). Accessibility within open educational resources and practices for disabled learners: A systematic literature review. Smart Learning Environments, 7(1), 1.

\section{Publisher's Note}

Springer Nature remains neutral with regard to jurisdictional claims in published maps and institutional affiliations.

Submit your manuscript to a SpringerOpen ${ }^{\odot}$ journal and benefit from:

- Convenient online submission

- Rigorous peer review

- Open access: articles freely available online

High visibility within the field

- Retaining the copyright to your article

Submit your next manuscript at $\boldsymbol{\nabla}$ springeropen.com 